\title{
Climate and vegetation impacts on infrastructure cuttings and embankments
}

\author{
William Powrie* and Joel Smethurst \\ University of Southampton, Southampton SO17 1BJ, UK \\ * Corresponding Author, Email: wp@ soton.ac.uk
}

\begin{abstract}
A mature transport infrastructure such as that in the UK is often intensively used, but has key elements that were built without the benefit of a modern understanding of soil mechanics and geotechnical design. Operation of any transport infrastructure network is critically dependent on the performance of such elements, in particular cutting and embankment slopes. In a temperate European climate, seasonal winter wetting and summer drying impose potentially onerous cycles of loading that can precipitate both ultimate and serviceability failures, especially in vegetated slopes. Seasonal shrinkage and swelling of clay fill railway embankments can directly disturb railway track geometry, resulting in train speed restrictions that disrupt normal operations. Very wet winter periods can cause result in slope failures requiring closure of the line for repair and in some cases potentially serious train derailments. As part of an ongoing long-term research programme, observations from field instrumentation are being used to understand how weather and vegetation drive changes in water content and pore water pressure in the earthworks, in turn leading to ground movements. The field observations have also been used to develop and calibrate numerical models able to replicate weather-driven pore water pressure changes and slope failure. The lecture will summarise recent progress, and show how historical and current weather event sequences have been applied using the models developed to understand and assess slope deterioration processes under future climate scenarios up to and including the 2080s.
\end{abstract}

Keywords: Earthworks, Vegetation, Climate change.

\section{$1 \quad$ Introduction}

Many of the UK's railway earthworks were constructed over 100 years ago, and not to modern geotechnical engineering standards. Soils, normally excavated from nearby areas of cut, were end-tipped to form embankments with little or no mechanical compaction (Skempton, 1996). Suctions generated within large clods or lumps of clay during excavation, and the behaviour of these stiff lumps as aggregates when tipped, allowed the formation of steep slopes. This often resulted in large post-construction settlements, and slope collapse as the initial soil suctions dissipated. Similarly, cutting slopes were often constructed too steep, relying initially on the short-term undrained 
shear strength to stand, until long-term dissipation of negative excess (reduced) pore water pressures eventually caused collapse. Many old railway embankments and cuttings have continued to deteriorate, suffering serviceability problems and in some cases slope failure (Andrei, 2000; O’Brien, 2007; Briggs et al, 2017). This represents a major hazard to railway safety in the form of the potential for train derailments, and often long closures of the railway while earthworks are re-built. The greatest numbers of failures of earthworks occur during prolonged wet winters, when soil pore water pressures are high (Vaughan et al, 2004; Briggs et al, 2017).

Modern highway earthworks in the UK have been constructed since the start of the re-development of the trunk road and creation of the motorway networks from the 1960 's onwards. The embankments and cutting slopes are therefore much better engineered than those on the railway system; but in clays still suffer from occasional shallow and apparently climate-driven failures, which can cause minor disruption and require repair.

The seasonal nature of evapotranspiration and rainfall in the UK, with much higher evapotranspiration and generally lower rainfall during the summer than winter, causes annual cycles of soil drying and wetting. The effective stress changes caused by the seasonal changes in pore water pressures/suction can cause steady increases in shear strain in clay slopes (Kovacevic et al, 2001; O'Brien, 2007), eventually leading to progressive or ratcheting failure.

The seasonal variations in water content can result in shrinkage and swelling of the soil, particularly in older embankments constructed of high-plasticity clay (Loveridge et al, 2010). This affects the line and level of the railway track, leading to train speed restrictions and ultimately to expensive track re-levelling work. Many old railway embankments have become heavily vegetated with trees following the cessation of general vegetation management after end of steam locomotives on British railways in 1968. Vegetation, especially trees, exacerbates summer drying through root water abstraction. Hence the greatest track deformations are found to occur near mature trees growing close to the embankment crest (Andrei, 2000).

Pore water pressure changes in earthworks are highly transient and complex. They are driven by rainfall infiltration, evaporation and plant transpiration, and variations in soil permeability with depth - including those resulting from changes to soil structure associated with plants and desiccation cracking. This makes understanding, and modelling pore water pressure changes quite complex. In addition, the mechanisms of soil deterioration, and slope deformation and failure are still not that well understood. In northern Europe, climate change is expected to bring hotter drier summers, and slightly warmer and wetter winters (Jenkins et al, 2010). This will exacerbate the problems of serviceability and stability described above; hence understanding the influence of climate change on pore water pressures and soil deformations is important for the future management of earthworks.

This paper describes both observations and numerical modelling carried out by the authors over a number of years, sometimes in conjunction with other project partners and stakeholders, to understand changes in water content and pore water pressure and ground movements in earthworks caused by climate and vegetation. The aim of the work has been to start to develop a quantitative understanding of the effects of climate 
change on earthworks, and their implications for the management of earthworks in the future.

\section{Field observations of pore water pressures and deformations in earthworks}

\subsection{Seasonal cycles of pore water pressure below a grass surface: a modern highway cutting}

Smethurst et al $(2006,2012)$ described the instrumentation and monitoring of a modern highway cutting near Newbury, UK (Fig. 1), to measure changes in water content and pore water pressures, focusing particularly on the drying effects of the shallow (grass and herb) vegetation cover. The cutting was in London Clay, a stiff overconsolidated deposit, with an angle of 16 degrees to the horizontal. The instrumentation installed included piezometers and tensiometers to measure pore water pressures and suctions, and neutron probe access tubes and TDR probes to measure soil volumetric water content. A weather station was installed at the site to record local rainfall, and the parameters (temperature, humidity, solar energy and windspeed) needed to make a site specific estimate of plant evapotranspiration. The site also has an interception trench to capture surface runoff and flow through the top soil, with the volume of runoff/through-flow being measured using a flow gauge.

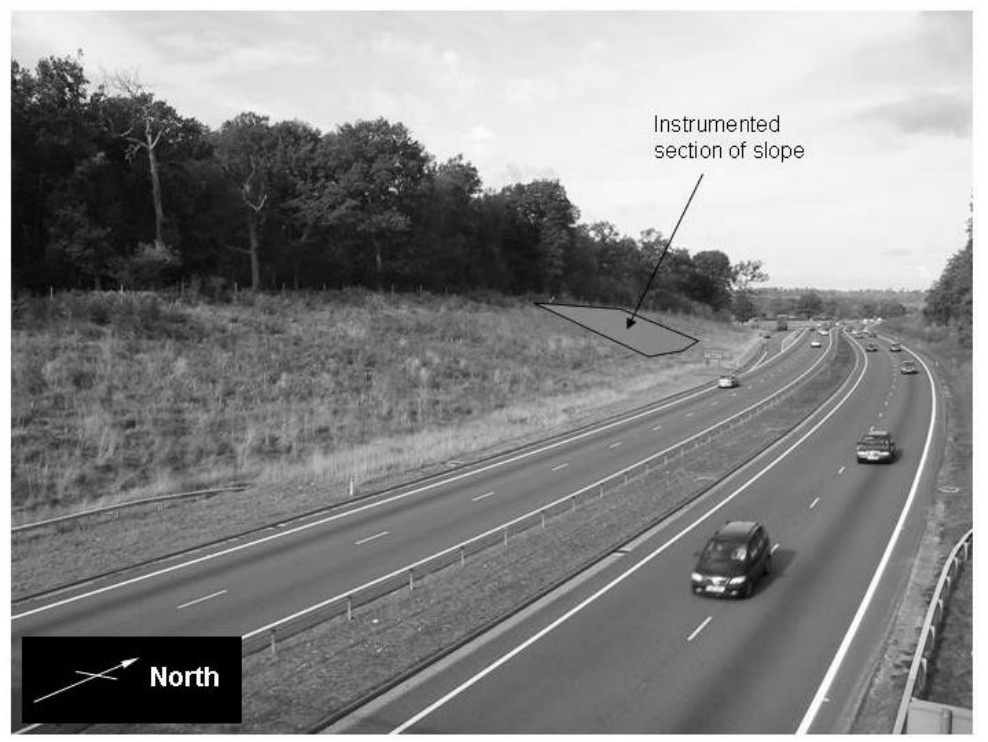

Fig. 1. Instrumented London Clay cutting at Newbury, Berkshire, photographed in 2003. (From Smethurst et al, 2006). 
Smethurst et al (2012) describe and analyse in detail the first six years (2003-2008) of monitoring data from the site. In particular, the recorded data were used to: i) calibrate a simple water balance model able to describe the wetting and drying of the major rooting zone; ii) show that the amount of summer rainfall had a significant effect on the drying and suctions developed in the slope during summer; and iii) in conjunction with an extended 50-year rainfall record, describe the return periods of the winter and summer wetting and drying events observed.

In particular, it was found that the grass and herb vegetation could root to about $800 \mathrm{~mm}$ depth, causing the major soil drying, and larger summer suctions (>100 kPa) to occur in the plant root zone. In a drier summer (return period $\sim 1$ year in 10), negative pore water pressures were measured to about $3 \mathrm{~m}$ depth. In wet winters, pore water pressures returned to near-hydrostatic from about $0.5 \mathrm{~m}$ below the ground surface, showing that the relatively shallow drying caused by grass and herb vegetation is not reliably maintained through the winter when most plant transpiration stops.

The site has also been used to investigate permeability and potential changes in permeability resulting from summer desiccation cracking in the clay soil. It is apparent that during the summer, drying of the soil by plants opens up a network of fine fissures, of typical spacing 50-100 mm, through the surface (rooting zone) of the slope. These cracks increase the bulk permeability of the clay, and along with the desiccation of the clay at the surface and thus its ability to absorb water, mean that even quite intense rainfall events are accepted into the profile, resulting in no runoff occurring. The summer cracking means that water is able to infiltrate fairly readily into the surface of the slope, particularly in the autumn months. A series of permeability measurements was carried out at the site, using double-ring infiltrometer and borehole bail out tests, to seek to characterise the permeability of the soil, and how it changes in the surface zone. Dixon et al (2018) report the results of these experiments, together with observations from other similar clay slopes.

Data from the site continue to be recorded up to the present time. This gives, bar some small gaps where the datalogging systems have failed, a >15-year dataset. Shallow soil water content observations, measured using TDR ThetaProbes, are shown in Fig. 2 for 13 years of observations. This is plotted together with the surface soil water balance, calculated using rainfall and evapotranspiration at the site, and reported as soil moisture deficit (SMD), i.e. the amount of water required to refill the soil profile to field capacity. The model is explained in more detail by Smethurst et al (2006, 2012). The SMD and soil water content observations cover a mix of characteristically dry and wet summers, with substantial soil drying occurring in the summers of 2003, 2005, 2006, 2010 and virtually no soil drying occurring in the summers of 2007, 2008 and 2012, which were very wet.

A monitoring period of 13 years has allowed observation of the water content and pore water pressure changes for a range of wet and dry summers and winters. It has also been possible to observe combinations of these in immediate succession. However, with light vegetation cover, the drying and wetting cycle for a given year is not much affected by the previous year, as the shallow depth of summer drying and absence of significant evapotranspiration in the winter mean that the profile nearly always re-wets in late winter or early spring. 


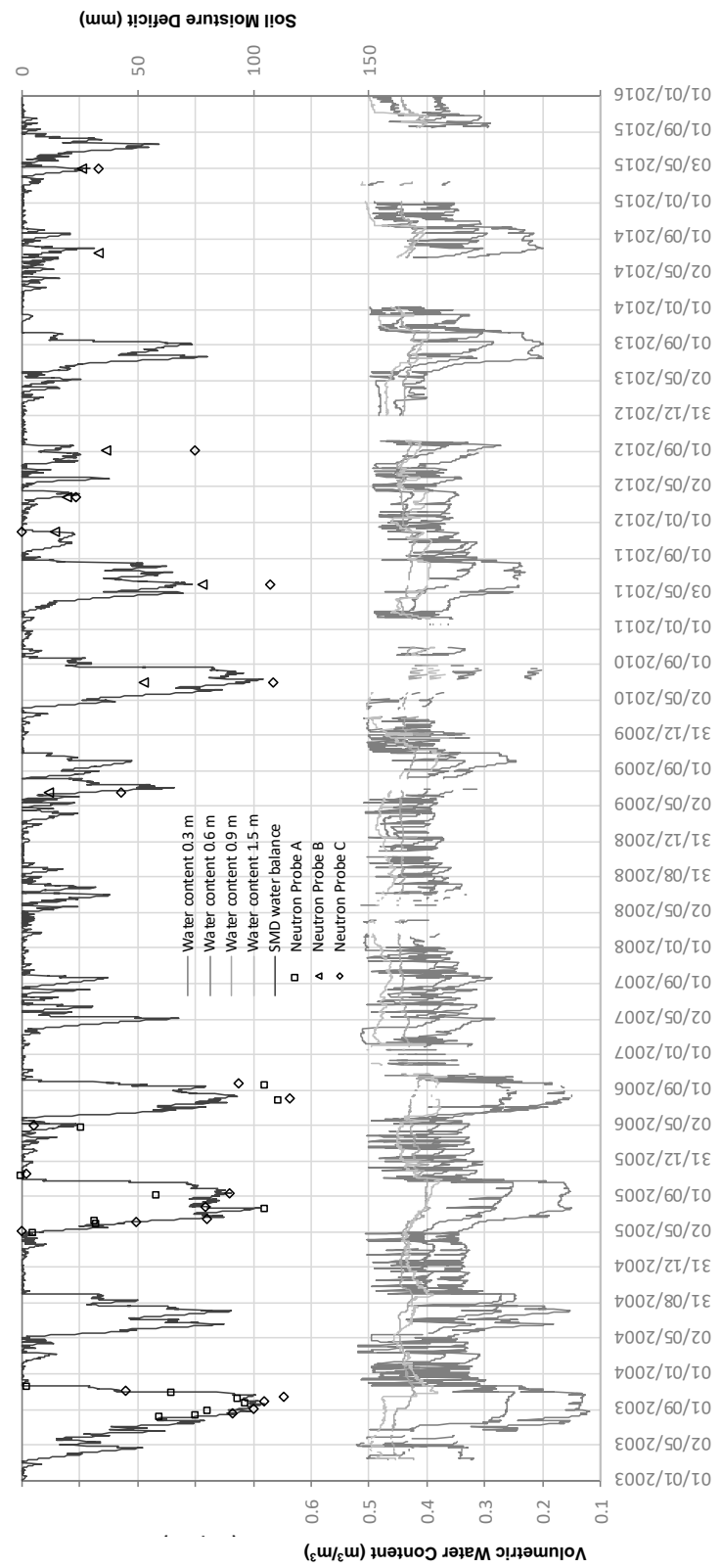

Fig. 2. Continuous measurements of soil water content using Delta-T ThetaProbe at four depths, over 13 years 2003 to 2015 (lower graph), plotted with soil moisture deficit obtained from the water balance model of the root zone (upper graph). The upper plot also contains a series of points representing discrete measurements of soil moisture deficit obtained from neutron-probe water content measurements. 


\subsection{Changes in pore water pressures caused by mature trees: an old railway embankment}

Trees will typically root much deeper than grass, herbs and small shrubs, and as a result can have a much larger impact on soil drying. In a study carried out for Network Rail, Smethurst et al (2015) installed instrumentation in the spring of 2006 to measure the changes in water content, pore water pressure, and soil vertical and lateral movement in an old tipped London Clay railway embankment at Hawkwell, Essex, UK. Shrinkage of the clay embankment caused by large deciduous oak and ash trees was giving rise to poor track quality and the need to apply train speed restrictions. The embankment was monitored for a year with the trees in place. The trees were then removed from the upper two-thirds of the embankment slope within the instrumented section, leaving trees only on the bottom one-third of the slope. After tree felling, monitoring continued for a further four years. Fig. 3 shows the embankment after tree removal.

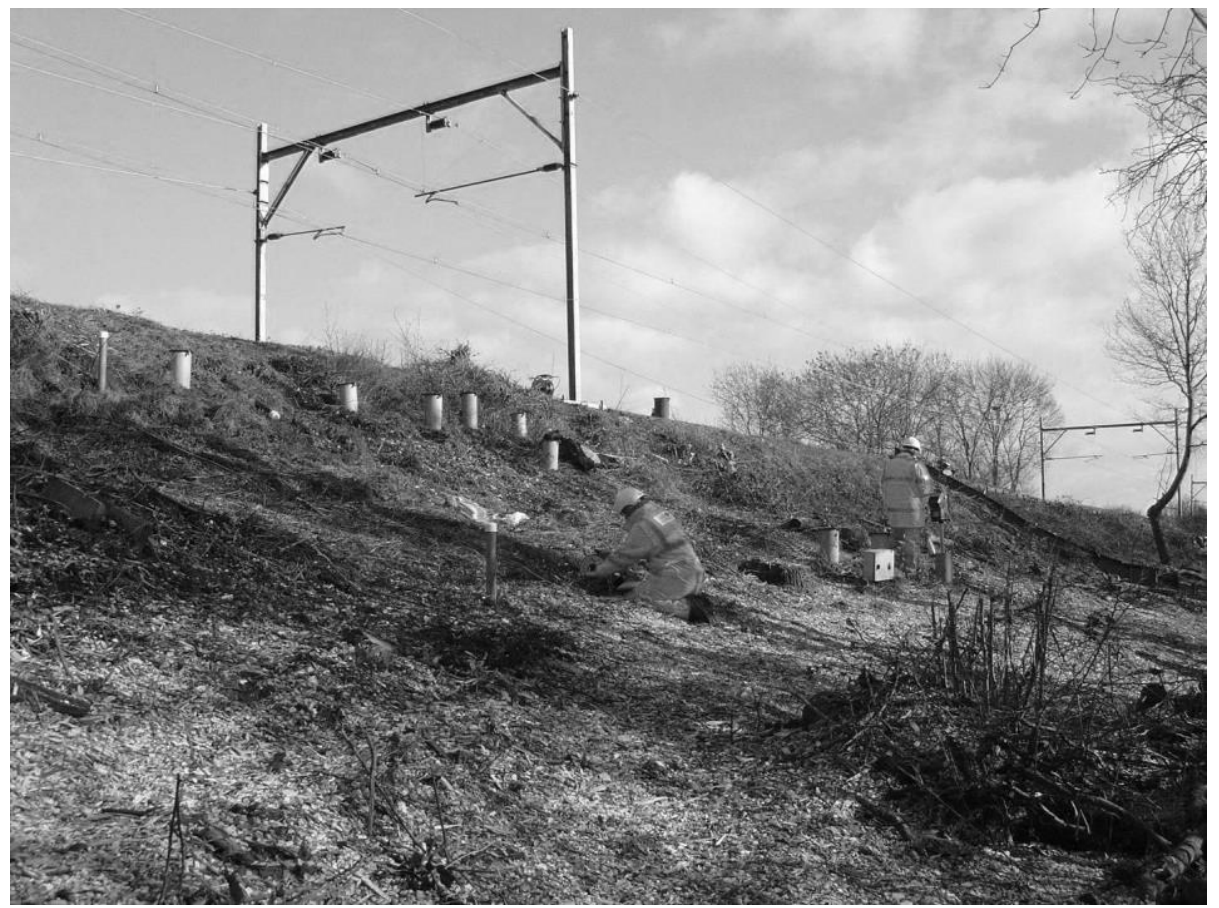

Fig. 3. Hawkwell railway embankment in 2010,3 years after tree removal, and shortly after a second vegetation clearance to remove scrubby re-growth from the slopes. (From Smethurst et al, 2015).

Magnet extensometers installed close to the crest of the embankment slope showed a significant vertical shrink/swell movement of about $40 \mathrm{~mm}$ over the first year of 
monitoring. After tree removal in early spring 2007, seasonal (particularly summer drying) movements were substantially reduced, although the embankment underwent a gradual underlying swelling (Fig. 4).

Water content measurements, made approximately monthly using a neutron probe, and pore water pressure/suction measurements, showed that initially the embankment had a considerable moisture deficit, with pore water suctions extending to about $3 \mathrm{~m}$ below the base of the embankment. This moisture deficit had likely built up over several preceding drier years; average annual evapotranspiration by tree cover is potentially greater than the average annual rainfall $(\sim 600 \mathrm{~mm})$ in this part of the UK, meaning that trees may consistently try to remove more soil water than is replenished by rainfall. Removal of the mature trees in early spring 2007 led to a steady re-wetting of the embankment, with infiltration from the slope surface downward into the soil profile. This led to the gradual diminution of the significant soil moisture deficit, bringing the soil closer to saturation with a consequent loss of soil suctions.

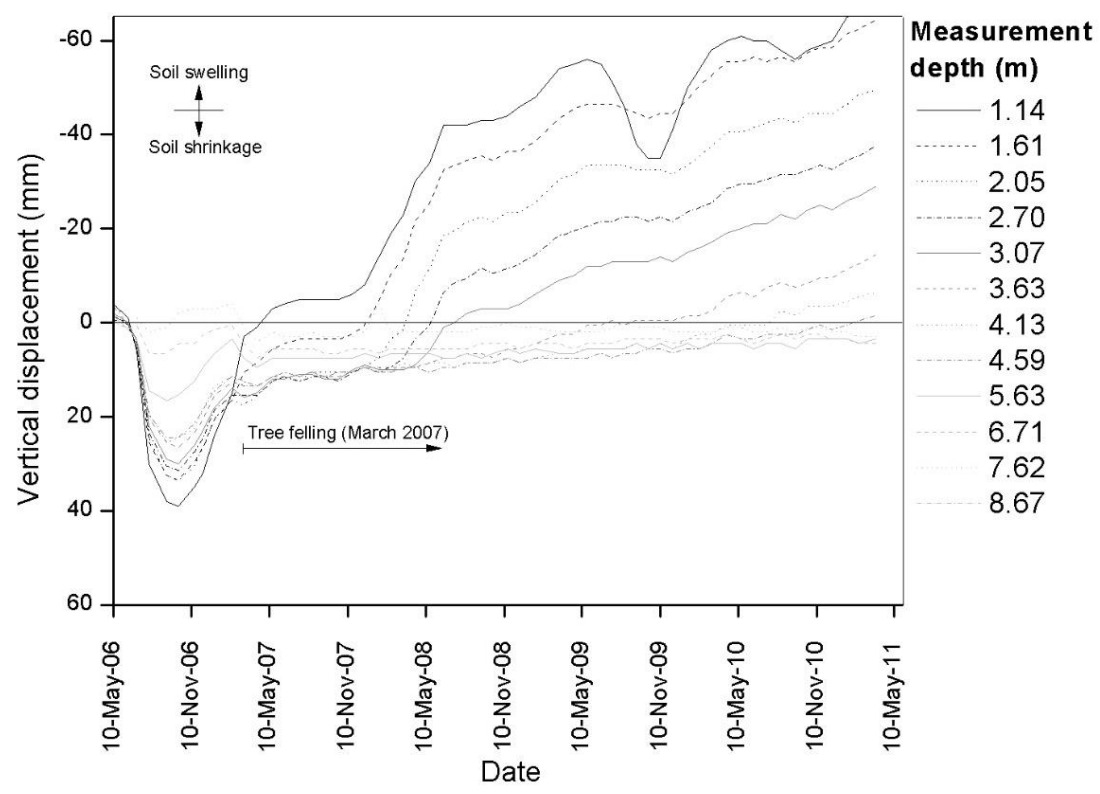

Fig. 4. Vertical soil displacements measured using a magnet extensometer installed close to the crest of the slope. (Redrawn from Smethurst et al, 2015).

After tree removal, the slope revegetated naturally with a mix of some scrubby vegetation and areas of grass. This much smaller vegetation cannot transpire as much water as a dense tree cover, and has a much shallower rooting system (roots to $\sim 0.5$ to $0.75 \mathrm{~m}$, whereas the trees may have been rooting to $2.0 \mathrm{~m}$ or more). This changed the balance between rainfall and evapotranspiration, allowing more water to infiltrate into the embankment - particularly during winter, when evaporation and transpiration are low. 
Tree removal from the instrumented section was effective in substantially reducing seasonal shrink/swell movements at the crest of the embankment, although the soil moisture deficit and suctions that aid slope stability were lost as the embankment rewetted. A slope close to saturation is prone to increases in pore water pressure during heavy rainfall, which could lead to slope instability. A careful balance therefore needs to be struck between maintaining stability and reducing seasonal displacements. This may require a more limited or selective vegetation clearance, such as the managed removal of just high-water-demand trees, than was carried out in this case.

Briggs et al (2013a) investigated railway track level monitoring data for a series of sites that were either at-grade on a clay foundation, or on a clay embankment. Existing tree location, height and species information was obtained for the sites; or where this was not available, site visits were made to record it. The species of trees and their distance horizontally from the track were correlated with seasonal track displacements. This was compared with the National House Building Council (NHBC) guidelines on building near trees, which categorises trees species into high, medium and low water demand. The NHBC guidance defines a distance of influence over which a tree may damage shallow foundations, as $1.25 \times$ the tree height from a building foundation for high water demand trees, and 0.75 and $0.5 \times$ the tree height for medium and low water demand tree species. Plotting the track displacement against the distance of the tree from the track normalised by tree height showed that most high water demand trees within $1.25 \times$ the tree height of the track were causing appreciable (up to 30 $\mathrm{mm}$ ) seasonal vertical movements (Fig. 5). As mature trees can be up to $20 \mathrm{~m}$ tall, this would suggest that all high water demand trees (including species such as oak, poplar and willow) should be removed if possible, from a zone up to $25 \mathrm{~m}$ laterally from the track, if damaging ground/track movements are to be avoided. In some cases, much of this distance would be outside the land owned by the railway, and in the case of Hawkwell, $25 \mathrm{~m}$ would also extend beyond the base of the embankment, greater than the extent of the trees clearance carried out at the site.

Medium and low water demand trees were generally found not to cause very significant ground movements, suggesting that where possible, high water demand trees should be replaced by species of low and/or medium water demand.

\subsection{Wet winter pore water pressures}

In 2000/2001 the UK experienced the wettest weather since records began in 1766 . Across England and Wales an average of $503 \mathrm{~mm}$ of precipitation was recorded from September to November 2000, which is $196 \%$ of the 1971-2000 long-term average. This wet autumn was preceded by wet winters in 1998/1999 and 1999/2000 (Ridley et al, 2004), and a wetter than average summer in 2000, creating very wet soil conditions and pore water pressures likely to have been higher than at any point in the preceding 250 years. A significant number of earthworks failures were recorded across the transport system (Briggs et al, 2017). In the winter of 2000/2001, Ridley et al (2004) made a series of measurements of pore water pressures in old clay railway embankments on the London Underground system, to try assess the influence of the very wet period of weather. 


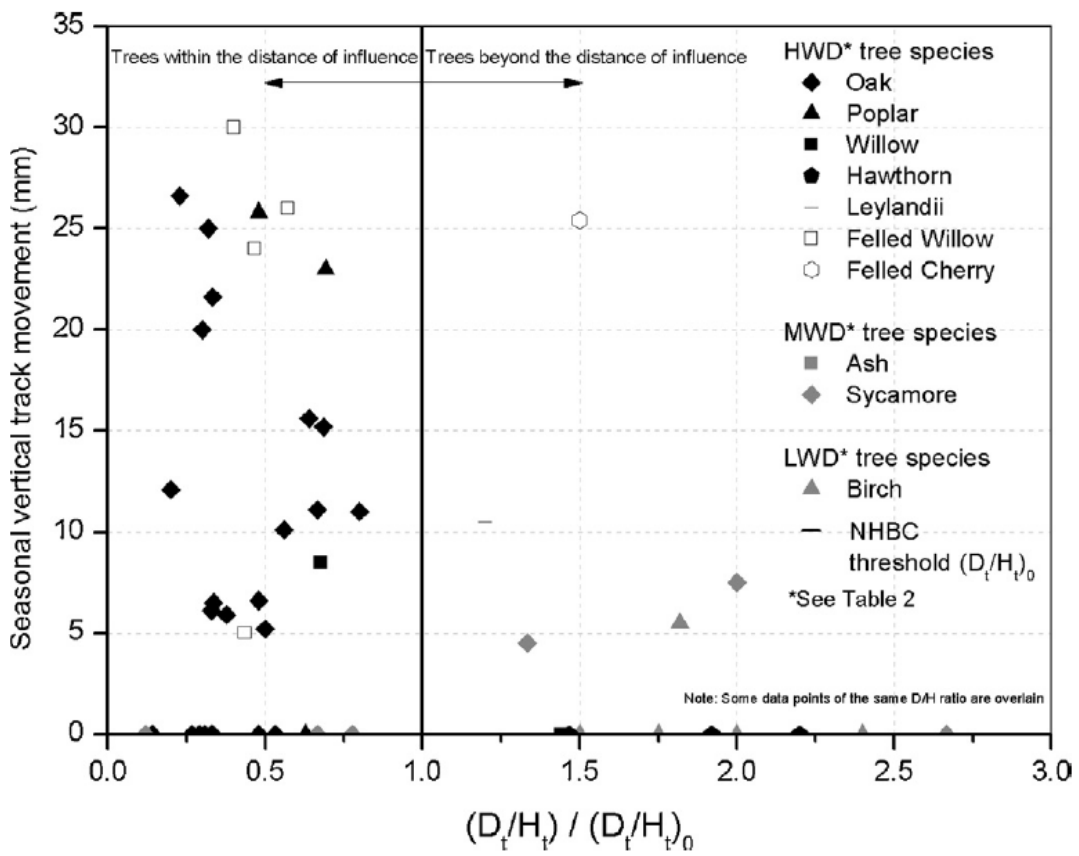

Fig. 5. Measured seasonal vertical track movements plotted against the ratio of the distance from the nearest running rail to the trunk of the tree $\left(\mathrm{D}_{\mathrm{t}}\right)$ and the height of the tree $\left(\mathrm{H}_{\mathrm{t}}\right)$. The ratio $\mathrm{D}_{\mathrm{t}} / \mathrm{H}_{\mathrm{t}}$ is normalised by $\left(\mathrm{D}_{\mathrm{t}} / \mathrm{H}_{\mathrm{t}}\right)_{0}$, which is the same ratio given in the NHBC guidance for each of high, medium and low water demand trees. The plotted study sites were thirteen embankments, one cutting, and two sites 'at grade'. (From Briggs et al, 2013a).

The Ridley et al (2004) piezometer measurements were re-analysed by Briggs et al (2013b), who added contextual data such as embankment fill soil type, foundation material, slope aspect, borehole/peizometer location on the slope, slope angle and slope vegetation type, where this information was available. Most of these factors were found not to have any correlation with the measured pore water pressures; the only significant relationship was between pore water pressure and the foundation material on which the embankment was constructed. Clay embankments constructed above a higher permeability (terrace gravel or chalk) foundation were found to maintain low pore water pressures, significantly below hydrostatic from the clay slope surface. Those on a clay foundation, of possibly lower permeability than the tipped clay fill, were generally found to have much higher pore water pressures, tending towards hydrostatic from the slope surface (Fig. 6). So even during an extremely wet winter, clay embankments with good underdrainage maintain low pore water pressures, and are more likely to remain stable, compared with those sitting above clay. This behaviour was confirmed by back analyses using an unsaturated finite element analysis of a typical earthwork, with suitable imposed infiltration boundary conditions (Briggs et al, 2013b). 


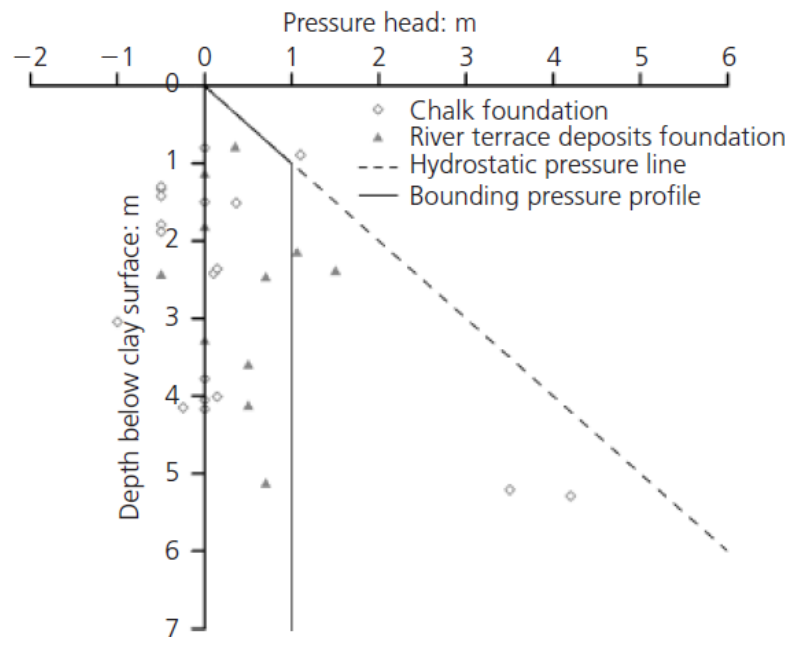

(a)

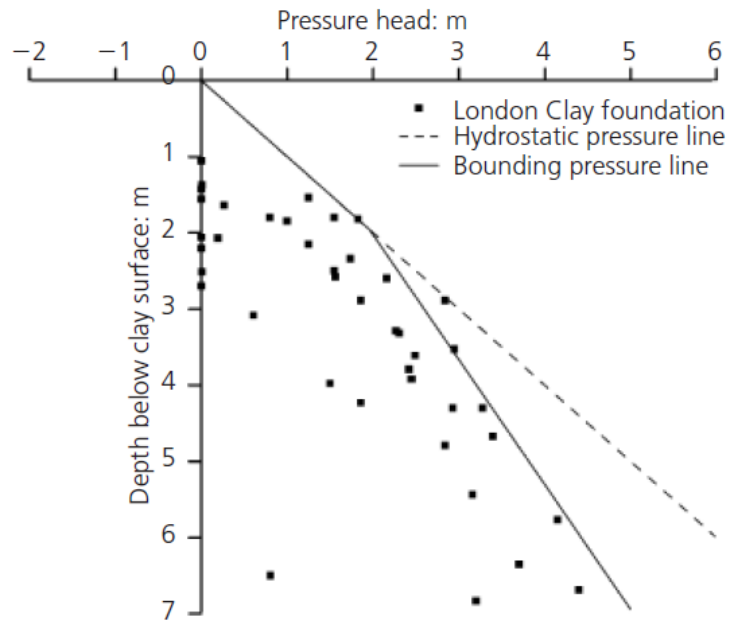

(b)

Fig. 6. Pore water pressures plotted (as pressure head in metres) with depth below the clay slope surface, for: (a) clay embankments above a high permeability (chalk or terrace gravel) foundation; (b) clay embankments above a clay foundation. (From Briggs et al, 2013b). 


\section{Modelling vegetation, climate and slope failures}

Numerical modelling has been used to understand the mechanisms by which rainfall infiltration and plant water abstraction cause pore water pressure changes with the instrumented earthworks. The instrumented earthworks have provided comprehensive observations of changes in soil water content and pore water pressure (and in some cases the associated soil movements), and of rainfall and the other weather parameters such as temperature and humidity needed to estimate evapotranspiration.

However, the movement of water through the slope is controlled by the permeability and water retention behaviour of the soil, which may change with time, as e.g. the soil cracks. Plant water abstraction behaviour is controlled by root depth and density, the limits on the evaporative capacity of the atmosphere and the ability of the plants to generate root suction. Some of the parameters needed to describe these behaviours are uncertain and difficult to measure. For example, to characterise properties of the likely heterogenous old tipped embankment fill at sites like Hawkwell would require an extensive testing campaign; measurements of root depth and density ideally require a deeper trial pit, which is expensive to do safely. Thus back analysis of the field monitoring case histories can be used either to confirm mechanisms of behaviour, or to assess operational numerical values for the controlling parameters.

Heppell et al (2014) developed a one-dimensional hydraulic finite difference analysis of the Newbury slope profile, and used this to explore the uncertainty around seasonal changes in soil permeability and water retention parameters, resulting particularly from the opening and closing of cracks in the surface (rooting zone) of the slope, and plant parameters such as root water uptake distribution with depth. The model used a sophisticated kriging algorithm to fit parameter values so that the soil water content changes in the model matched closely those in the field. The Heppell et al (2014) modelling demonstrated that the permeability and water retention behaviour of the soil needed to change over the course of a year for the model to replicate the measured behaviour. Even then, they probably (inadvertently) did not change the permeability sufficiently to reproduce the full influence of clay cracking; this resulted less good fits to the field data in autumn and early winter, as the soil profile re-wet.

The Hawkwell site was back analysed by Briggs et al (2016), using the commercial finite element software Vadose/W to try to match the observed changes in soil water content and pore water pressure. Using a set of carefully considered climate, soil water retention, permeability and plant parameters (rooting depth, and root water abstraction with depth), it was found that the model could replicate fairly well the field observed changes. Specifically, the model demonstrated the development of a persistent soil moisture deficit over several years (the model started in 2001 and the instrumentation in 2006), and the correct re-wetting and loss of suction on tree removal (Fig. 7).

There were some differences in the magnitude of suctions (which were larger in the model than in the field), and in rates of change (with the model wetting slightly faster than in the field). These are likely to have been caused by differences in perme- 
ability and water retention behaviour between the model and field; in this set of simulations, water retention and permeability were not allowed to change with time and were fixed throughout the full modelling period of 11 years. The modelling philosophy was not to try to replicate in detail every expected behaviour (e.g. hysteresis in wetting and drying behaviour, and dual permeability caused by cracking were not modelled), but to demonstrate that a simple model capturing the principal physical processes was able to replicate the key physical behaviours observed. To model the trees growing on the earthwork, it was found to be essential to abstract water from the model over a deep tree rooting zone of $3 \mathrm{~m}$; this enabled the trees to develop the persistent soil moisture deficit maintained over winter.

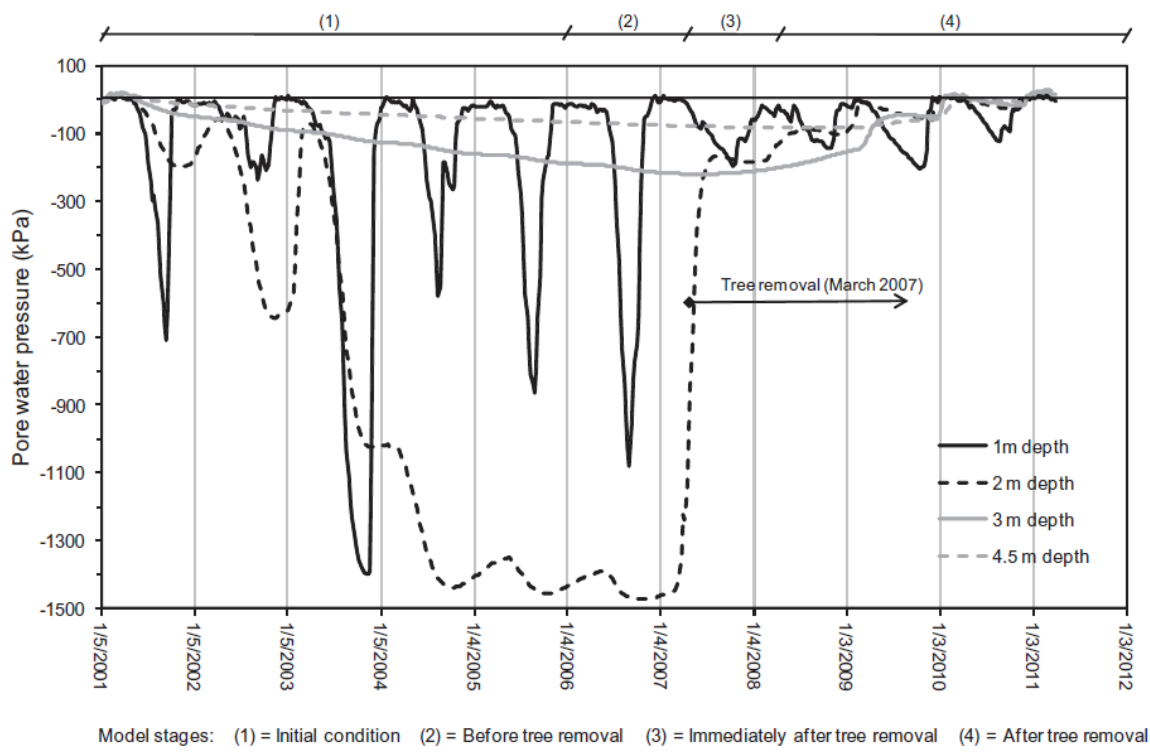

Fig. 7. Pore water pressure variations within the finite element model at mid-height of the south facing Hawkwell embankment slope, over an eleven year model run. (From Briggs et al, 2016).

\section{$4 \quad$ Assessing the effects of future climate}

Clarke and Smethurst (2010) used the UK Climate Impacts Programme (UKCIP) 2002 climate forecasts to investigate the potential impact of climate change on seasonal and longer-term changes in soil water content. They adopted a simple water balance model, based on the model used by Smethurst et al (2006) to investigate soil wetting at drying at the Newbury site. This showed that based on the High Emissions scenario (Hulme et al, 2002), in 2080 the UK would experience generally significant- 
ly hotter and drier summers, leading to an average annual maximum soil moisture deficit (SMD) for a clay soil under rough grass cover of about $160 \mathrm{~mm}$, compared with about $120 \mathrm{~mm}$ for the period 1961-1990. The major implication for this is the likely change in the probability of very dry soil conditions occurring in summer: Fig. 8 shows a probability plot for maximum annual SMD with points representing 19611990 (based on actual weather data), and the 2080's (synthetic data, based on UKCIP02). The driest year in the period 1961-2005 was 1972, when a maximum soil moisture deficit of $172 \mathrm{~mm}$ was calculated. This has a cumulative probability of $2.2 \%$, consistent with a return period of 1 in 45 . This is likely to become the average year in the 2080's. In other words, the past extremes will simply become the future norm.

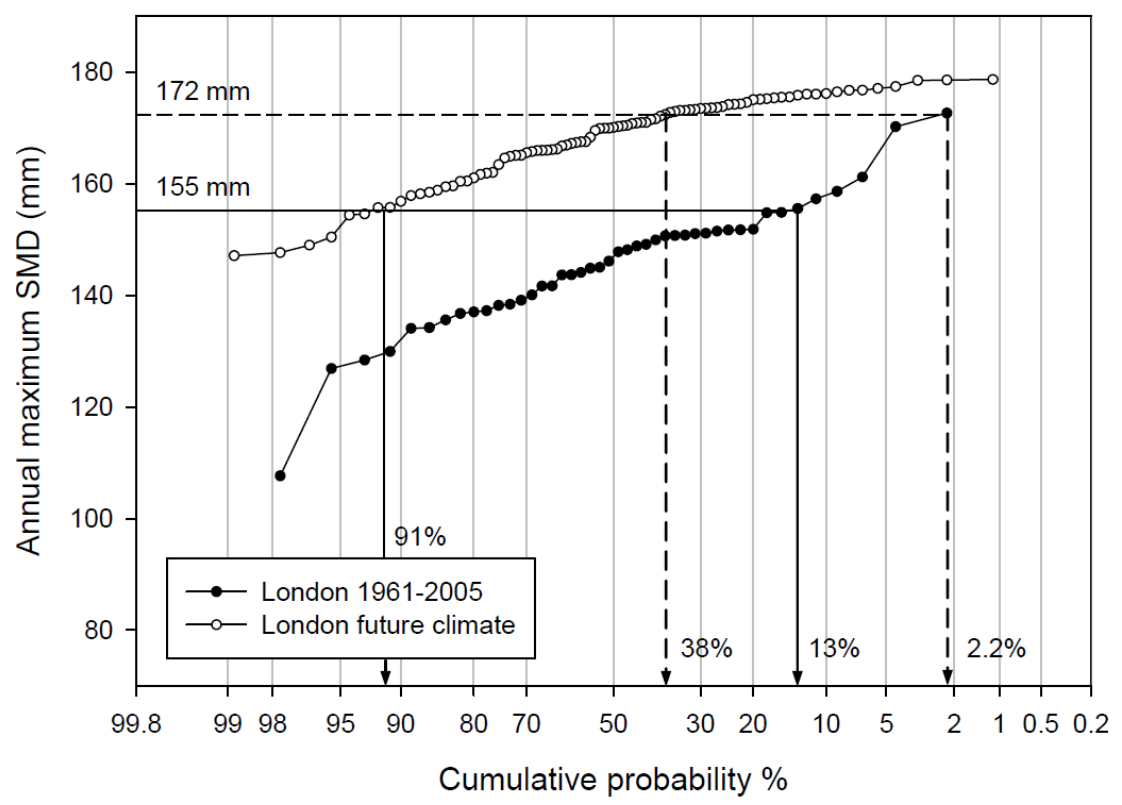

Fig. 8. Annual maximum SMD for 1961-2005 plotted against cumulative probability (so that the average year is at the $50 \%$ position, and significantly dry years causing a large SMD, such as the 1 in 20 dry year, are plotted at the 5\% level). The plot illustrates the change in relative probability of maximum SMD at London for the historically dry years of 1995 (172 mm) and 2003 (155 mm). (From Clarke and Smethurst, 2010).

A more recent set of simulations to investigate weather driven slope instability in clay infrastructure earthworks, and the impacts of climate change on failure has been carried out as part of the major EPSRC iSMART project, involving several UK partner institutions (Newcastle University, Loughborough University, Durham University, University of Southampton, Queens University Belfast and British Geological Survey). The simulations, carried out mainly by Newcastle University, used a coupled combination of the software FLAC and SHETRAN to model generic clay slopes typi- 
cal of those found on the UK rail and highway networks. SHETRAN was used to model atmosphere-plant-soil interactions.

The pore water pressure and water content changes generated close to the slope surface in response to climate were then imposed on a similar model in FLAC to generate pore water pressures deeper within the slope, and soil deformations. The soil constitutive model used incorporates strength reduction with plastic strain, representing peak, critical and residual states of a clay soil. Seasonal shrink and swell movements in the slope develop increasing plastic strains starting from the toe of the slope, leading eventually to progressive failure. The model also has a gradually decreasing permeability with depth, intended to model the higher permeability close to the slope surface caused by cracking, evidenced by the observations reported by Dixon et al (2018). Figure 9 shows the reduction in factor of safety for a range of London Clay slopes, all $8 \mathrm{~m}$ high, and of differing slope angle. The steepest slopes fail most rapidly. Owing to a problem with the undrained stage of the model, the times to failure here are rather too short, but nonetheless the analyses demonstrate the likely mechanism of failure, which is influenced by the higher permeability surface zone and forms parallel to the slope surface.

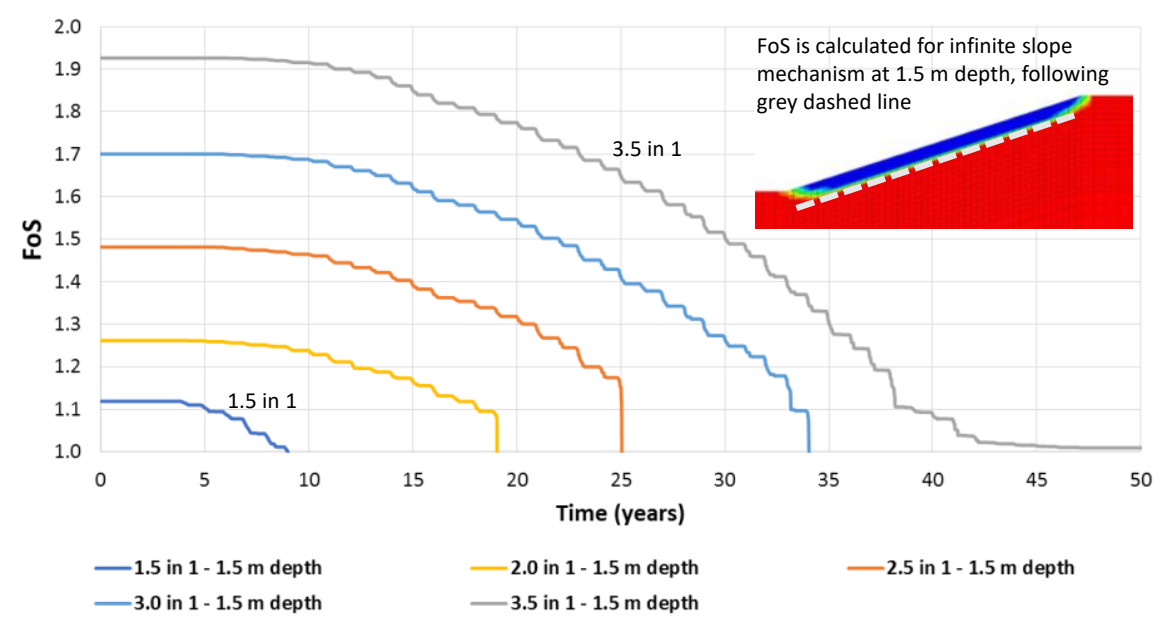

Fig. 9. Factor of safety versus time for a series of $8 \mathrm{~m}$ high London Clay slopes, of differing angle. The displacement of the model slope at failure is shown inset, and show that the finite difference model fails with a fairly shallow planar mechanism. (Figure courtesy of Dr Peter Helm, Newcastle University).

In 2009, the UK Climate Programme revised their global climate models and brought out a revised set of future climate scenarios for the UK, along with a weather generator tool that produces synthetic plausible future climate. The outputs are probabilistic to represent the uncertainty in the global climate models, and are intended to be used probabilistically, for example with a Monte-Carlo simulation where the mod- 
el (of the slope) is run many times with different versions of weather input, and the results considered stochastically. The 2002 climate datasets used by Clarke and Smethurst (2010) were deterministic - e.g. only one version of a future climate was used. As the iSMART FLAC/SHETRAN model took quite a long time to complete extended (150 year) simulations, this also needed deterministic climate scenarios. A methodology to convert weather generator outputs into a set of deterministic scenarios representing differing future time periods and emissions scenarios was developed, and is described in detail by Woodman et al (2018).

A new project called ACHILLES, funded by EPSRC and which started in July 2018 , is building on the iSMART work described above, to continue to improve models of deterioration and failure and the impact of climate change on geotechnical assets. As well as infrastructure earthworks, the project will also consider other long, linear geotechnical infrastructure, including flood embankments and pipeline bedding. ACHILLES will also incorporate outputs from the EPSRC Rooting for Sustainable Performance project, which is currently developing new understanding and models for how plants roots mechanically stabilise the soil: a further important way in which plants influence slope stability, alongside the generation of soil suctions.

\section{Conclusions}

- High quality observations from field instrumentation, obtained over monitoring periods of up to 15 years, have been used to determine the influence of both seasonal and longer duration periods of weather on changes in soil water content and pore water pressures in infrastructure embankment and cutting slopes.

- Rainfall can be much more variable than evapotranspiration, and can have a significant influence on soil water content and pore water pressures. By setting an observed period of rainfall in context within a longer record, it is possible to ascribe approximate return periods to observed soil water/pore pressure conditions. This is helpful to understand whether observations have captured extreme years.

- Shallow vegetation such as grass and herbs generally only root to about $800 \mathrm{~mm}$ depth in clay soils, and are not capable of establishing soil drying that is not then completely reversed by winter rainfall. It is possible to model the effect of such shallow vegetation on the soil using a simple water balance.

- Mature trees can root to much greater depths than grass, herb and small shrub vegetation, and remove greater quantities of groundwater through root water uptake. In clay soils, this has the potential to cause significant vertical ground movements, in the order of tens of mm, which can cause serviceability problems for railway tracks and other infrastructure supported by earthworks. The much larger depth over which root water abstraction takes place means that evapotranspiration can be larger than rainfall infiltration, allowing the development of semi-permanent soil moisture deficits, and pore water suctions that are maintained through the winter months. These are beneficial to embankment slope stability. 
- Clay embankments founded on a permeable stratum such as chalk or gravel are underdrained, and can maintain low (well below hydrostatic) pore water pressures even in extreme wet years. Pore pressures will be significantly greater in embankments founded on clay, and these are at greater risk of failure during wet weather.

- Calibrated numerical models have been used both to understand the mechanisms by which rainfall infiltration and plant water abstraction cause water content and pore water pressure changes in slopes, and explore the effects of uncertain parameters such as soil permeability and water retention behaviour.

- Both a simple and more complex approaches have been used in numerical models to investigate the impact that future climate change will have on soil water contents, pore water pressures and slope deformations. Climate change is expected to bring hotter drier summers with a greater maximum soil moisture deficit, and larger winter to summer cycles in both water content and pore water pressures. Modelling shows that past extreme years are likely to become the norm (average year) in the future. This is likely to increase problems related to clay shrink and swell, and may exacerbate weather-driven modes of progressive slope failure.

\section{Acknowledgements}

The work presented in this paper was funded by Network Rail (Hawkwell embankment study), and the UK Engineering and Physical Sciences Research Council (EPSRC) grant numbers GR/R72341, EP/F063482 and EP/K027050. Kevin Briggs work as an EngD student at Southampton was funded by EPSRC and Mott MacDonald. Support from Highways England with monitoring at the Newbury site is also gratefully acknowledged.

\section{References}

1. Andrei, A. Embankment stabilisation works between Rayners Lane and South Harrow Underground stations. Ground Engineering. 33 (1), 24-26 (2000).

2. Briggs, K. M., Loveridge, F. A. \& Glendinning, S. Failures in transport infrastructure embankments. Engineering Geology. 219, 107-117. (2017).

3. Briggs, K., Smethurst, J. A., Powrie, W., \& O'Brien, A. S. The influence of tree root water uptake on the long term hydrology of a clay fill railway embankment. Transportation Geotechnics, 9, 31-48. (2016). DOI: 10.1016/j.trgeo.2016.06.001

4. Briggs, K. M., Smethurst, J. A., Powrie, W., \& O'Brien, A. S. Wet winter pore pressures in railway embankments. Proceedings of the Institution of Civil Engineers - Geotechnical Engineering, 166 (5), 451-465. (2013b). DOI: 10.1680/geng.11.00106

5. Briggs, K. M., Smethurst, J. A., Powrie, W., O'Brien, A. S., \& Butcher, D. Managing the extent of tree removal from railway earthwork slopes. Ecological Engineering, 61(Part C), 690-696. (2013a). DOI: 10.1016/j.ecoleng.2012.12.076

6. Clarke, D., \& Smethurst, J. Effects of climate change on cycles of wetting and drying in engineered clay slopes in England. Quarterly Journal of Engineering Geology and Hydrogeology, 43(4), 473-486. (2010). DOI: 10.1144/1470-9236/08-106 
7. Dixon, N., Crosby, C.J., Stirling, R., Hughes, P.N., Smethurst, J. A., Briggs, K., Hughes, D., Gunn, D., Hobbs, P., Loveridge, L., Glendinning, S., Dijkstra, T., \& Hudson, A. In situ measurements of near surface hydraulic conductivity in engineered clay slopes. Under review with Quarterly Journal of Engineering Geology and Hydrogeology. (2018).

8. Heppell, J., Payvandi, S., Zygalakis, K. C., Smethurst, J. A., Fliege, J., \& Roose, T. Validation of a spatial-temporal soil water movement and plant water uptake model. Géotechnique, 64(7), 526-539. (2014). DOI: 10.1680/geot.13.P.142

9. Hulme, M., Jenkins, G.J. \& Lu, X. et al. Climate Change Scenarios for the United Kingdom: The UKCIP02 Scientific Report. Tyndall Centre for Climate Change Research, School of Environmental Sciences, University of East Anglia, Norwich. (2002).

10. Jenkins, G. J., Murphy, J. M., Sexton, D. M. H., Lowe, J. A., Jones, P. \& Kilsby, C. G. UK Climate Projections: Briefing report. Version 2, December 2010. Met Office Hadley Centre, Exeter, UK. (2010).

11. Kovacevic, N., Potts, D. M. \& Vaughan, P. R. Progressive failure in clay embankments due to seasonal climate change. Proc. 15th Int. Conf. Soil Mech. Geotech. Engng, Istanbul 3, 2127-2130. (2001).

12. Loveridge, F. A., Spink, T. W., O’Brien, A. S., Briggs, K. M. \& Butcher, D. The impact of climate and climate change on UK infrastructure slopes. Quarterly Journal of Engineering Geology and Hydrogeology. 43 (4), 461-472. (2010).

13. National House Building Council (NHBC). National House Building Council Standards, Chapter 4.2, Building Near Trees. NHBC, Milton Keynes. (2007).

14. O'Brien, A. S. Rehabilitation of urban railways - investigation, analysis, and stabilisation. In Cuellar V., Dapena E., Alonso, E. et al (Eds.), Proceedings of the 14th European conference on soil mechanics and geotechnical engineering, Madrid. Vol. 1, 125-143. Rotterdam, the Netherlands: Millpress. (2007).

15. Ridley, A., McGinnity, B., \& Vaughan, P. Role of pore water pressures in embankment stability. Proceedings of the Institution of Civil Engineers - Geotechnical Engineering 157(4), 193-198. (2004).

16. Skempton, A. W. Embankments and cuttings on the early railway. Construction History 11, 33-49. (1996).

17. Smethurst, J. A., Briggs, K. M., Powrie, W., Ridley, A., \& Butcher, D. J. E. Mechanical and hydrological impacts of tree removal on a clay fill railway embankment. Géotechnique, 65(11), 869-882. (2015). DOI: 10.1680/geot.14.P.010

18. Smethurst, J. A., Clarke, D., \& Powrie, W. Seasonal changes in pore water pressure in a grass covered cut slope in London clay. Géotechnique, 56(8), 523-537. (2006). DOI: 10.1680/geot.2006.56.8.523

19. Smethurst, J. A., Clarke, D., \& Powrie, W. Factors controlling the seasonal variation in soil water content and pore water pressures within a lightly vegetated clay slope. Géotechnique, 62(5), 429-446. (2012). DOI: 10.1680/geot.10.p.097

20. Vaughan, P. R., Kovacevic, N. \& Potts, D. Then and now: some comments on the design and analysis of slopes and embankments. Advances in geotechnical engineering: Proceedings of the Skempton Conference, Imperial College, London, Vol. 1, 241-290. (2004).

21. Woodman, N., Smethurst, J. A. and other iSMART authors. Synthetic weather data for modelling long term deterioration in geotechnical assets. In preparation. (2018). 